\title{
The NPW framework in future-oriented studies of cultural agency
}

\author{
MATTI KAMPPINEN
}

$T$ he network of possible worlds, or NPW for short, offers a theoretical framework where cultural agency can be systematically linked with such central concepts of future-oriented studies as future path, scenario, actor, vision, trend, weak signal, future awareness and foresight development. Time is embedded in a NPW in two ways: the NPW itself is temporally structured, and the actors navigating within the NPW are equipped with cognitive models of time. The framework can be applied not only in the study of theoretical and empirical aspects of cultural agency, but also in the political management of human societies, including the forecasting of religious and ethnic dynamics. It provides tools for capturing the special characteristics of cultural agency. Therefore, it is an essential tool in understanding the religious and ethnic futures of Europe.

\section{Introduction}

Our commonsense theory of human action takes time and temporality for granted: we form intentions and act them out in order to have an impact on the world of the future. ${ }^{1}$ Temporality pervades our existence, as we experience ourselves, and the world we know, to be existing in the present, future and past.

Let us look at a story, not so fictitious: One morning a young Iraqi man packed his bags and started his journey to Northern Europe. He packed all the cash he had been able to raise in order to prepare for the journey. He had a cognitive model of a possible world in which he would pay for his boat trip or train ticket. He pictured himself in various situations and chose to prepare himself for the coming circumstances. He expected to get to Northern Europe in six months. He planned beforehand and was capable of pursuing

1 The NPW framework presented here is based on a book on risk theory (Kamppinen et al. I 995) and especially on a textbook chapter I wrote together with Pentti Malaska and Osmo Kuusi (Kamppinen et al. 2003). Sections here dealing with intentional systems theory draw on Kamppinen 20 Io. 
a possible world of better living. Had he not been born in Iraq, or had recent history been otherwise, the future for him would have looked quite different. The choices he and others had made in the past had impacted on the present situation and on the diversity of possible worlds that he could picture as he looked to the future. If this particular Iraqi man had not had the model of possible worlds in his mind, he would not have left in the first place, and the future of Europe would be easier to predict. Thinking and acting in terms of possible worlds is what makes us human; it is in the very essence of human existence.

Past, present and future worlds are arranged in a temporal order and most of the time we can tell quite confidently how they are organized. On the other hand, our current experience takes place in the present moment (or the actual world), from which vantage point we look at past and future possibilities. The future events travel in time towards us, pervade the actual world, and transform into past events. Our commonsense theory of human action encapsulates the core idea of NPW, the network of possible worlds, in which we are situated in a temporally ordered (directed) framework - the actual world being painted in more intense colours:

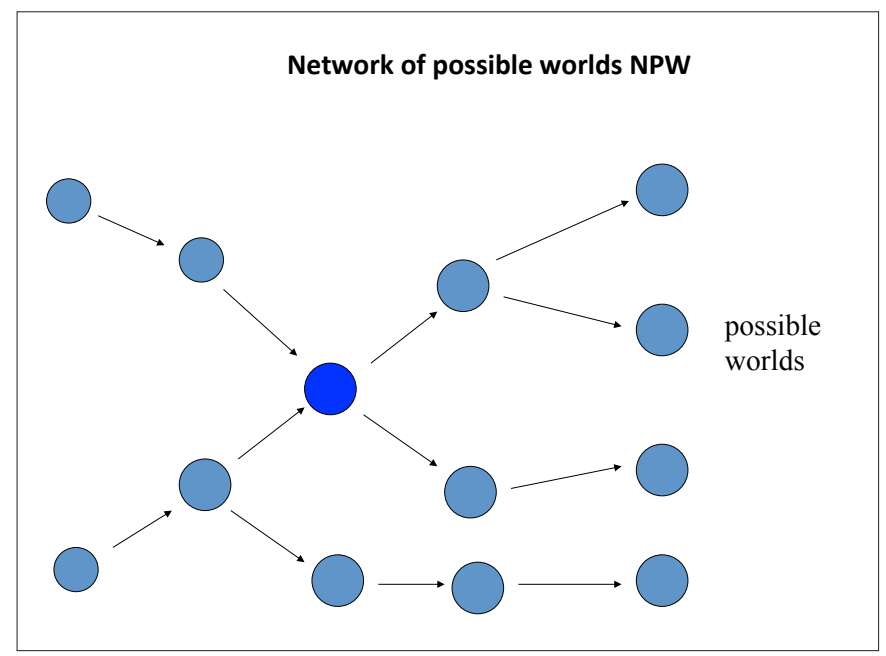

Fig. 1.

NPW is a theoretical framework that can be applied to cultural studies, especially in understanding agency and the future dynamics of religious and ethnic actors. 
Initially, possible worlds semantics was developed for epistemic and deontic logics as well as for action theory (von Wright I 95 I, Hintikka I 975, Copeland 2002), but the general idea has been applied in various fields of research (Dolezel 2010, Ejerhed and Lindström 201 2). I do not intend to apply the various axioms of modal logic to cultural studies, but rather hope to utilize the idea of possible worlds in cultural studies in order to highlight how time and human action are connected. Furthermore, I am not the first to propose that the concept of agency can be fruitfully understood within the framework of possible worlds. Especially scholars in futures research such as Pentti Malaska and Mika Mannermaa (Malaska and Mannermaa r 985), Osmo Kuusi (1999), Nicholas Rescher (1997), Wendell Bell (1 997), Richard Slaughter (2012) and many others have developed a future-oriented framework that has the commonsense theory of human action at its foundation. In cultural and religious studies, Thomas Lawson (200 I), Laura Leming (2007) and especially Jörg Rüpke (2015) have theorized about agency.

My principal claim is that in order to be able to discuss the religious and ethnic futures of Europe we need to employ the NPW framework, or something like it, because what it means to talk about futures is to talk about possible worlds, their accessibility, the future paths leading from one world to another, and constraints affecting the future paths as well as the accessibility of possible worlds (Carmon 20r6). Hence, the NPW framework provides us with the tools to understand the world as a dynamic and systemic whole with different future options. Moreover, the religious and ethnic actors planning their future paths (where to stay, where to go, what to hope for) have their respective NPW models in their minds and cultures, by means of which they navigate in the world of uncertainty. My related claim is that the essential constituents in the NPW framework are the cognitive models of risk, time and superhuman agency.

\section{Agency in terms of intentional systems theory}

One may ask how relevant is the commonsense theory of human action and the theory of time which is embedded in it? For cultural studies, commonsense theory is extremely relevant. There are fields of research where commonsense theories do not have much bearing, such as physics, cosmology or chemistry, but in those areas of research where humans are treated as agents or intentional systems, commonsense theories do provide important theoretical insights. 
I will briefly illustrate the concept of an intentional system by means of how we talk about sports. The game of soccer (European football) is a cultural scene where there are actors following rules, publicly articulated roles for players, shared cognitive models for all players and for spectators, and the typical venue at which the game takes place. There are elements that are required for that process to be a game of soccer, and there are elements that can be exchanged for others without the game losing its individual character. The venue, for example, could be a soccer stadium or a playing field, the goal posts could be made of steel or wood, or the goals could be marked out with rocks or tin cans. The players can use high-end soccer shoes or play barefoot.

The set of required elements of the game includes that the actors are playing with the distinctive cognitive models of soccer, as well as the associated beliefs and desires that enable them to identify the ball, the players, the goal, and to act accordingly: to keep the ball, kick it and score goals when the opportunity arises. If the actors had no clue as to what they were doing, the activity would not be a game of soccer, even though they might be moving themselves and the ball according to the rules of soccer. The beliefs and desires of the players constitute the game, and we can successfully describe, explain and predict their behaviour on the basis of these beliefs.

Our intuition concerning the soccer players is solid. What it means to play soccer is to have players with the appropriate beliefs and desires. We treat the players as intentional systems, to use a term introduced by the philosopher Daniel C. Dennett, in his article 'Intentional systems' (reprinted in Dennett I98I). An intentional system is a system that can be understood (described, explained and predicted) by means of ascribing beliefs, desires, intentions and other representations to it. The notion of an intentional system articulates the commonsense theory of human action, and captures the hard core of how we construe human action in futures research as well: actors navigating a network of possible worlds (Herman 2008, Slors 2007).

\section{Navigating the network of possible worlds}

The universe as we know it contains a number of possible courses of events in the sense that things could have gone otherwise. As events unfold, it may happen that we are lucky in trying to affect them, or some other time, it may turn out that we run out of luck, despite of our efforts to change the course of events (Rescher 200I). 
Courses of events are causally dependent upon various things: upon ourselves and our capabilities, our fellow human beings, the laws of nature, economics, complex hybrid situations of natural laws and social commitments and so on. Some causal factors in our lives are more predictable than others, some are even known to scientific research, whereas some are just assumed to exist and have causal power. Some of these assumed causal factors are interpreted in terms of superior beings, anthropomorphic agents whose causal powers are greater than ours. In certain cultural settings, these superior beings are elements of religions; they are revered and ritually manipulated, whereas in certain other cultural settings the superior beings are feared and taken into account as necessary features of technological progress. What is common to the superior beings of religions and the risks of modern societies is that they provide challenging antagonists in the games of life, in the various projects of navigating a world of uncertainty.

Intentional systems face uncertainty. We experience ourselves as beings situated in the network of possible worlds. Some possible worlds are behind us, some lie in the future; some of them are accessible to us, and some are beyond our reach for one reason or another. We scholars believe all this. In addition, we believe that the people we study and facilitate are very much like us. They, the study objects, are cognitively competent, culturally-groomed actors finding their way in the networks of possible worlds. Navigating a world of uncertainty encapsulates the dynamics of intentional systems. The very reason for building internal representations and beliefs or desires is to cope with uncertainty, the possible future worlds. Intentional systems utilize cultural resources for the purposes of navigating in the world of uncertainty. Let us explicate the elements of decision making any intentional system uses in the network of possible worlds.

The central concept is the possible world. It refers to the state of affairs that could obtain or not. It is a conceivable state of affairs, in the sense in which the Austrian philosopher Alexius von Meinong used the term Gegenstand - anything that can be thought about (Sajama and Kamppinen 1987). A world in which the majority of Europeans are Muslims is a possible world.

A possible world, 'pw', can be defined as a collection of those states of affairs that obtain in that world. If, for example, we have a world were the states of affairs 'p', 'q' and 'r' obtain, it can be denoted as

$$
\mathrm{pw}=\{\mathrm{p}, \mathrm{q}, \mathrm{r}\}
$$


The possible world 'pw"' where only 'p' and ' $\mathrm{q}$ ' obtain and ' $\mathrm{r}$ ' does not obtain, is partially similar to 'pw', sharing some features with it

$$
\mathrm{pw}^{*}=\{\mathrm{p}, \mathrm{q}, \operatorname{not} \mathrm{r}\}
$$

The possible world is an ontological partner of a cognitive model: it is a collection of those states of affairs that would actualize the corresponding cognitive model. Therefore, it includes those topics or issues that are specified by cognitive models which, in turn, motivate and guide human action. For example, if the actor is acting with a conscious intention to settle permanently in Northern Europe, then the possible world that figures in his NPW contains the state of affairs being settled in Northern Europe. We must understand possible worlds at least partly in relation to those mental states that constitute them. As we include, for example scientific facts in possible worlds, these facts are in turn knowable through theories by means of which we are able to grasp them.

Just as cognitive models can be based on anything, so possible worlds can contain any states of affairs. I can imagine a world where an omnipotent god rules the world, but that world is hardly accessible from the world we know. In interesting ethnographic contexts, possible worlds are sensibly connected. The possible world where the god communicates with human beings is linked with the possible world where one can ask god to protect one during one's travel to Europe.

That is, possible worlds are connected to each other by means of two links, constraints and accessibility. Different constraints such as biological, economic, moral, psychological or physical aspects control the future paths, the connections between possible worlds. For example, the possible world where all humans are free to travel can be reached by means of various future paths, but most of these paths are constrained by political, economic or psychological barriers. The possible world where the Christian God is seen as being identical with the Allah of Islam and Krishna of Hinduism, is conceptually possible but, from the viewpoint of some adherents, not morally or culturally possible. Constraints can be viewed as one-step relations between possible worlds.

The accessibility of possible worlds is a multi-step relation that sums up the pertinent constraints: a possible world may be accessible politically and biologically, but not theologically, for instance. The world where Islam 
is critically studied by the majority of Islamic theologians, is not accessible culturally or ideologically from the current possible world.

Times change, as the saying goes, and this means that the constraints and accessibility relating to possible worlds change. In most of Europe, for example, it was not imaginable a hundred years ago that churches and other buildings central to Christianity could be used for profane purposes. Now the possible world where churches are rented out as performance venues or marketplaces has become the actual world. Economic, political, cultural and ideological constraints have changed and this change has brought about the world that was once deemed inaccessible.

Possible worlds form networks, where they are linked by temporallyordered paths. Future paths, for example, that spring from our current actual world, are constrained by natural and social boundary conditions that, in turn, affect the accessibility of the future worlds awaiting at the ends of future paths, as illustrated in the figure below:

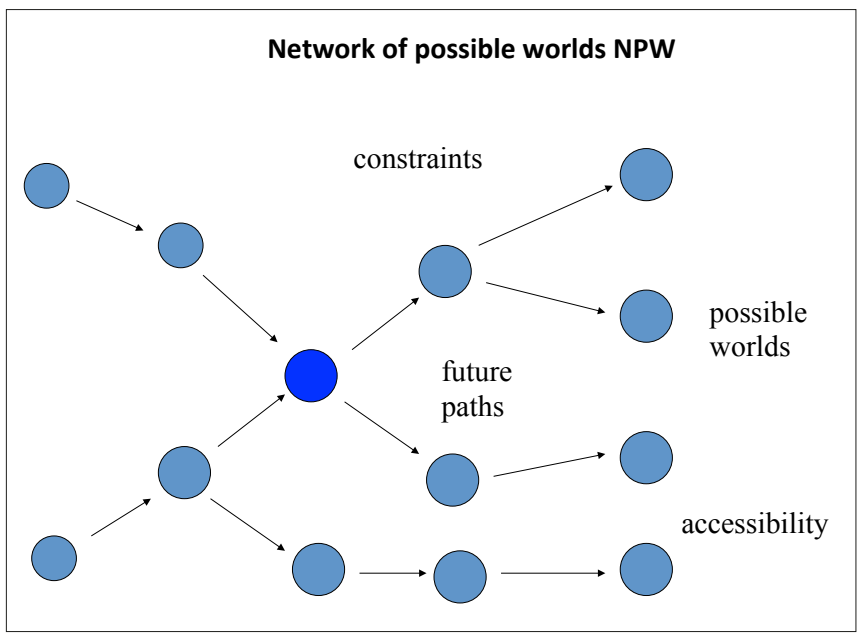

Fig. 2.

The network of possible worlds is temporally ordered: that is, the possible worlds are organized in strict, partial ordering ' $\mathrm{T}$ ' so that ' $\mathrm{T}$ ' is antisymmetric, anti-reflexive and transitive. So, for example, if the event ' $x$ ' is earlier than the event ' $y$ ', then ' $y$ ' is not earlier than ' $x$ '. Or, if ' $x$ ' is earlier than ' $y$ ' and ' $y$ ' is earlier than ' $z$ ', then ' $x$ ' is earlier that ' $z$ '. 
The temporal skeleton of the network of possible worlds defines what it means to talk about the future in the first place. When navigating a world of uncertainty, intentional systems have several more specific cognitive tools for the purposes of decision making and risk management.

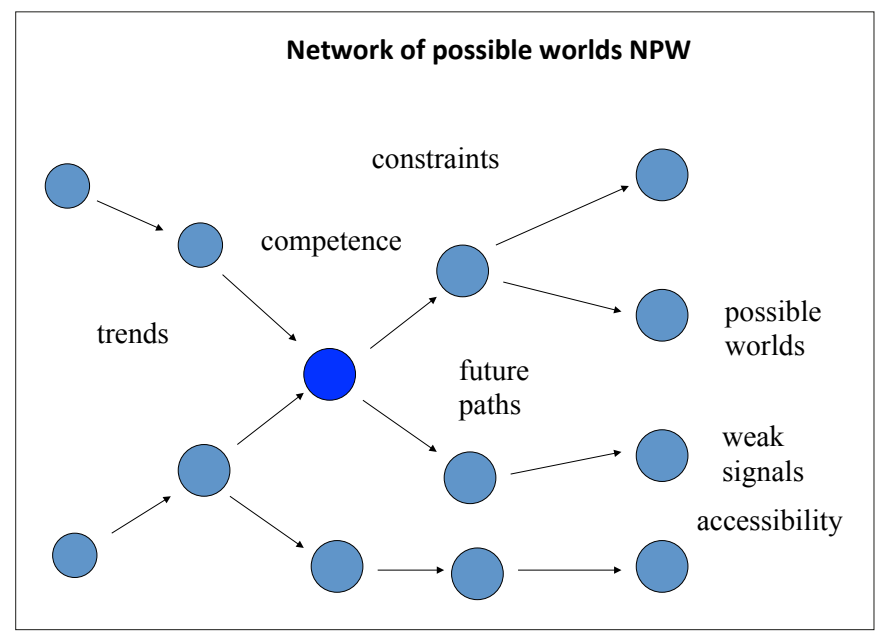

Fig. 3.

In the above figure, we have some further concepts of futures research in the NPW framework (drawn from Kamppinen et al. 2003). Weak signals are properties attributed to future possible worlds, and they are assumed to indicate themselves in the actual world. A weak signal is thus a relation that links possible worlds together so that the feature indicated by the signal grows more salient as we travel into the future. Therefore, weak signals travel back in time, metaphorically, as they are assumed to provide information from the future possible worlds. Trends are properties of possible worlds; possible worlds are ordered in time and connected by future paths, and a trend is strengthened when its presence in a chain of possible worlds is greater, and weakened when its presence is less. An actor's competence relates to the actor's properties; how he or she is able to move along the future paths, construct novel possible worlds, manage the constraints and have access to different possible worlds. Actors have different competencies, the central resources being their cognitive models, to which we will return below.

We can also add further concepts into the NPW for the purpose of illustrating how the NPW framework organizes the central concepts of 
future-oriented religious studies. The following concepts are common stock in futures research (see, for example, Bell 1997 and Slaughter 20 I 2), but my aim here is to illustrate how they can be systematically captured in terms of the NPW framework (as articulated in Kamppinen et al. 2003).

Scenario is a chain of possible worlds, a relevant future path. What makes it relevant is that there are possible worlds along the road or at the other end that have high levels of positive or negative utility for some actor operating with the NPW in question. Vision is a model of a particular possible world nested in the NPW where highly positive utilities become actual, and mission is a model of an actor's part in realizing the vision: what choices to make when future paths offer alternative ways to proceed. Strategy is a collection of norms that indicate how to apply decision criteria in various situations, at junctures where there are several alternative future paths. Future maps, as well as the pictures or images of the future, are partial models of the NPW, models that highlight some aspects and hide others. The notion of future awareness (or future consciousness) is also explicable by means of a NPW. Future awareness is a cognitive model or experience in which the actor situates himself in the NPW, thus seeing himself in a temporally-ordered framework. To activate future awareness, or to facilitate foresight, is to coconstruct models where participants situate themselves in different NPWs. Another related concept is risk. It can be thought of as the expected negative utility of any possible world and it will also be tackled below. Wild cards and black swans are features of possible worlds initially thought impossible or extremely improbable, yet which have impacts on relevant issues when they materialize. Alternative pasts are networks of past possible worlds, where the alternative courses of events are described alongside the course that actually took place.

Thus, the NPW framework enables us to systematize and highlight the central concepts of futures research.

Networks of possible worlds have a twofold presence: on one hand, the reality (independent of what we may think about it) seems to be a process, a network of possible worlds; on the other hand, we and other actors construct cognitive models of NPWs, by means of which we try to navigate what we take to be the real NPW. The cognitive component is therefore essential. 


\section{Cognitive models of risk, time and superhuman agency}

Cultural agency implies the existence of cognitive models. Our imaginary Iraqi man, described above, was equipped with cognitive models by means of which he went on to construct and implement his future plans and his future. In the NPW framework, cognitive models are tools for navigating the network of possible worlds. They portray simplified worlds, in which relationships bind entities together into systemic networks. Cognitive models are composed of concepts that enable people to have beliefs, desires and other mental states. These models concern not only the physical world and its material aspects, but also abstract entities such as social relationships, moral obligations, and superhuman agents (Johnson-Laird 1983 and 2005, Morgan et al. 200 I, Halford 2014). Models of risk provide maps with which to navigate the world of uncertainty (Saarinen and Kamppinen 2009, Vihervaara and Kamppinen 2009).

Cognitive models of risk provide tools for navigating the world of uncertainty in the sense that they provide us with information concerning relevant features of the situation. These features include, for example, the causal structure of the world, its ontological furniture and, most importantly, information on the other agents to be taken into account. Cognitive models of risk thus specify the game in which we find ourselves. Our Iraqi man estimates the probabilities of getting into Europe alive, and charts the main scenarios of what will happen after he has got there. He trusts his countrymen and is naturally suspicious of police and customs officers. The total risk landscape he foresees is based on the particular cognitive models that specify the possible harms and probabilities inherent in each area of life (Kamppinen and Wilenius 200I). Risks are culturally constructed not only in the sense that their existence and properties are conceptually specified, but also in the sense that material culture or technology is utilized in the processes of risk management and containment. Technological structures, together with other cultural systems, not only help to manage risks, but they create risks as well.

Risks reside in the networks of possible worlds. As we argued earlier, the network is temporally ordered. Cognitive models of time are the central tools of navigation (Hall I983, Bluedorn 2002, Eriksen 2001).

Why does time matter? In social life, timing is everything. Beginnings, ends, cycles, waiting, pasts and futures are the essence of human life. We 
humans have various ways of telling the right time, and the most complicated set of time-telling tools is our culture.

Our Iraqi man is used to waiting. The smuggler's boat navigating a short distance will not leave according to a set timetable, but will leave when it is time for it to leave, when there are enough passengers. His whole journey is filled with relative time, the temporal order in which time is dependent upon the processes themselves. In relative temporal order, time is generated by human actions, not superimposed by an external timetable (Levine 1997).

Absolute time is the time of schedules: it is ticking on and on, and we try to hurry up in order to meet the appointed times. Absolute time feels like it exists outside of us, and quite independently of us. It is the time of shared activities, carried out in accordance with a tight and unforgiving timetable. Train schedules, school schedules, as well as the yearly calendar of the Evangelical Lutheran Church of Finland have absolute temporal orders, at least for those who submit themselves to them.

Different societies possess different degrees of relative and absolute temporality - a society or a culture cannot be described as absolute or relative, but rather as consisting of various subsystems that are predominantly either absolute or relative. There are areas of life where the absolute temporal order prevails, and there are areas where the relative order prevails. During our daily lives, for example, we pass through areas of absolute order (e.g., a wakeup call, taking a bus to school or work) and areas of relative order (e.g., waiting for the kids to finish their breakfast, thinking first and then writing). In Northern Europe, our Iraqi man will face a society dominated by absolute temporality, timetables and punctuality, some of which will challenge his own cognitive models of time, dominated by relative views.

Another cultural distinction is the one between linear and cyclical temporal orders. In linear order, events are unique, and they can be plotted on a line that is strictly ordered in a before-after relation. The timeline has its beginning and also an end. Our historical imaginations as well as our perceptions of our life projects have a linear order: we start from one point in time and end up at another point. The cyclical order is one in which events recur and return. The weekly cycle, so strongly permeating our society is an apt example: Mondays come around again and again. As was the case with absolute and relative orders, so do the linear and cyclical orders co-exist and compete with each other (Eriksen 2001, Zerubavel 2003). Our Iraqi man will encounter different cycles (the working week, calendar rituals) in 
Northern Europe, as he compares the Islamic calendar with the 'standard' one.

Religious models of superhuman agents are prominent in those contexts where religious cultural resources tell people how to use their time, where the times have come from, and whether there are other temporal orders in the universe. Religions have a special interest in telling the right time. The times of our lives, the ritual calendar, the end of time, as well as eternity are all temporal constructions prevalent in religions.

Religions also transform relative times into absolute times, when the temporal order created by a superhuman agent is transformed and canonized into a calendar, for example.

Some religions describe human time as transient, changing, and decaying, whereas the temporal order of superhuman agents or forces is characterized as permanent, changeless or immutable. The eternal existence of the Christian or Islamic God, for example, represents everything that the human life is not.

In vernacular religions where the notion of eternity has no significant role, the realm of superhuman agents is characterized as permanent, slowly changing, larger than human life, but certainly not eternal. This feature of vernacular religions that have not been subjected to too much theological sophistication is interesting: one reason for the fact there are religions at all is definitely their capability to provide permanent configurations, superhuman agents that constitute systems that outlast human lives. Even in Christianity and Islam there are several human-like supernatural agents sharing the power of God: Jesus, the Virgin Mary, Mohammed, angels and saints, all of whom function as mediators between the human world and the realm of the supreme superhuman agent.

\section{Conclusion}

The commonsense theory of human action implies that human actors are intentional systems navigating in the network of possible worlds, or NPW. This provides a framework for integrating central concepts of futureoriented cultural studies as well as for articulating how cognitive models of risk and time figure in the study of agency: firstly, the NPW itself is temporally ordered, and secondly, actors are using cognitive models of time as they proceed along the future paths provided by NPWs. Therefore, the NPW framework provides a tool that captures the future-oriented action of 
the human being and enables us to talk about different futures in the first place. In addition, it helps us to understand situations when our model of the NPW differs from the models used by actors we wish to study or facilitate in navigating the NPW. Furthermore, it points out how the models of NPWs are constructed and sustained, and therefore collectively negotiated.

The NPW framework assumes that human action can be situated in various integral contexts; that is, it can be looked at from multiple perspectives (Bouhana and Wikström 20I I, Wikström 20 I 4). Suppose that, finally, our young Iraqi man has managed to travel to Finland and has applied for asylum. His action can be described in various ways, and all descriptions are equally true: (I) he has followed his vision; (2) he will provide Finland with a much-needed new member of the workforce; $(3)$ he will have added to the burden of European border control officers; (4) he will have become a suitable potential target for terrorist recruitment.

Each description situates the action in an integral context of possible worlds. If we are to assess the action, its nature, moral value, costs and benefits, the assessment depends on into which context the action is incorporated. The economic, social and political relevance of the action can be identified only after the context has been identified. It can be said that human action in the NPW framework is context dependent. In order to find out what an action is, we need to determine the context within which the action should be considered.

\footnotetext{
Matti Kamppinen is Senior Lecturer of Comparative Religion at the Department of History, Cultural Research and Arts Studies at the University of Turku. He has studied Amazonian folk religion, cognitive models of environmental risk, and philosophical issues in cognitive science and comparative religion. He has directed several multidisciplinary research projects and collaborated with ecologists, geologists, economists and psychologists. He has published articles in various journals such as Forest Policy and Economics, Method and Theory in the Study of Religion, Technology in Society, Computers and Society, The British Journal of Psychiatry and Futures.
}

\section{References}

Bell, Wendell, 1997. Foundations of Futures Studies, I-2 (New Brunswick, Transaction Books)

Bluedorn, Allen C., 2002. The Human Organization of Time: Temporal Realities and Experience (Stanford University Press)

Bouhana, N., and P. O. Wikström, 20 I I. 'Al Qaida-influenced radicalisation: a rapid evidence assessment guided by situational action theory' $R D S$ 
Occasional Paper, 97 (London, Home Office Research, Development and Statistics Directorate)

Carmon, Naomi (ed.), 2016. Immigration and Integration in Post-Industrial

Societies: Theoretical Analysis and Policy-Related Research (New York, Springer)

Copeland, B. S., 2002. 'The genesis of possible worlds semantics'. Journal of Philosophical Logic, 3 I , pp. 99-I 37

Dennett, Daniel C., I98 I. Brainstorms (Cambridge MA, MIT Press)

Dolezel, Lubomir, 201 . Possible Worlds of Fiction and History (Baltimore, The Johns Hopkins University Press)

Ejerhed, Eva, and Sten Lindström (eds.), 20 I 2. Logic, Action and Cognition. (New York, Springer)

Eriksen, Thomas H., 200I. Tyranny of the Moment: Fast and Slow Time in the Information Age (London, Pluto Press)

Halford, Graeme, 2014. Children's Understanding: The Development of Mental Models (London, Psychology Press)

Hall, Edward T., I983. The Dance of Life: The Other Dimension of Time (New York, Doubleday)

Herman, David, 2008. 'Narrative theory and the intentional stance', Partial Answers: Journal of Literature and the History of Ideas, 6, pp. 233-6o

Hintikka, Jaakko, I 975. 'Impossible possible worlds vindicated', Journal of Philosophical Logic, 4, pp. 475-84

Johnson-Laird, P. N., I983. Mental Models (Cambridge University Press)

2005. 'Mental models and thought', The Cambridge Handbook of Thinking and Reason, eds. Keith Holyoak and Robert Morrison (Cambridge University Press)

Kamppinen, Matti, 2010. Intentional Systems Theory as a Conceptual Framework for Religious Studies (Lewiston, The Edwin Mellen Press)

Kamppinen, Matti, Pentti Malaska, and Osmo Kuusi, 2003. 'Tulevaisuudentutkimuksen peruskäsitteet' [Fundamental concepts in futures research], Tulevaisuudentutkimus [Futures Research], 2nd edn, eds. Matti Kamppinen, Osmo Kuusi and Sari Söderlund (Helsinki, Finnish Literature Society), pp. I 9-54

Kamppinen, Matti, Petri Raivola, Pekka Jokinen, and Hasse Karlsson, I995. Riskit ybteiskunnassa [Risks in Society] (Helsinki, Gaudeamus)

Kamppinen, Matti, and Markku Wilenius, 200 r. 'Risk landscapes in the era of social transition', Futures, 33, pp. 307-I 7

Kuusi, Osmo, I 999. Expertise in the Future Use of Generic Technologies (Helsinki, VATT Publications)

Lawson, Thomas, 200 . 'Psychological perspectives on agency', Religion in Mind: Cognitive Perspectives on Religious Belief, Ritual, and Experience, ed. Jensine Andresen (Cambridge University Press), pp. I4I-72 
Leming, Laura M., 2007. 'Sociological explorations: what is religious agency?', The Sociological Quarterly, 48(I), pp. 73-92

Levine, Robert, 1997. A Geography of Time (New York, Basic Books)

Malaska, Pentti, and Mika Mannermaa, I985. 'Tulevaisuuden tutkimus tieteellisin perustein tapahtuvana toimintana' [Futures research as scientific inquiry], Tulevaisuudentutkimus Suomessa [Futures Research in Finland], ed. Pentti Malaska and Mika Mannermaa (Helsinki, Gaudeamus)

Morgan, Granger, Baruch Fischoff, Ann Bostrom, and Cynthia J. Atman, 200 I. Risk Communication: A Mental Models Approach (Cambridge University Press)

Rescher, Nicholas, I 997. Predicting the Future (Buffalo, SUNY Press)

-200 I. Luck: The Brilliant Randomness of Everyday Life (University of Pittsburgh Press)

Rüpke, Jörg, 20 I 5. 'Religious agency, identity and communication: reflections on history and theory of religion', Religion, 45, pp. 344-66

Saarinen, Sanni, and Matti Kamppinen, 2009. 'The models of nature and politics of sustainable development in the Peruvian Amazon', International Journal for the Sustainable Society, I(4), pp. 3 I I-24

Sajama, Seppo, and Matti Kamppinen, I 987. A Historical Introduction to Phenomenology (London, Croom Helm)

Slaughter, Richard A., 20I 2. To See with Fresh Eyes (Indooroopilly, Foresight International)

Slors, Marc, 2007. 'Intentional systems theory, mental causation and emphatic resonance', Erkenntnis, 67, pp. 32 I-36

Vihervaara, Petteri, and Matti Kamppinen, 2009. 'The ecosystem approach in corporate environmental management', Corporate Social Responsibility and Environmental Management, I6, pp. 79-93

Von Wright, G. H., I 95 I. An Essay on Modal Logic (Amsterdam, North-Holland Publishing Company)

Wikström, Per-Olof, 20 I 4. 'Situated action theory', Encyclopedia of Criminology and Criminal Justice, eds. G. Bruinsma and D. Weisbeud (New York, Springer)

Zerubavel, Eviatar, 2003. Time Maps: Collective Memory and the Social Shape of the Past (The University of Chicago Press) 